\title{
Error Analysis in the Operations of Algebraic Expressions of Grade 8 Students at Kalinga State University Laboratory High School
}

\section{Genalyn A. Ferrer}

Department of Social Science, Kalinga State University, Philippines

Received: 11 Oct 2020; Received in revised form: 12 Dec 2020; Accepted: 19 Dec 2020; Available online: 31 Dec 2020

(C)2020 The Author(s). Published by Infogain Publication. This is an open access article under the CC BY license

(https://creativecommons.org/licenses/by/4.0/).

\begin{abstract}
The study analyzed the errors committed by the grade 8 students when working with the operations of Algebraic Expressions at KSU - LHS for

SY (2018-2019). The study used the qualitative descriptive type research method which consisted of 135 students. The data were gathered through a series of tests and were properly analyzed. The common errors committed by the respondents when working with algebraic expressions were improper combination of terms, improper distribution, and cancellation, removing symbols of inclusions and sign errors. The students commonly commit errors on the following operations: Division, Addition and Subtraction and Multiplication.
\end{abstract}

When working on algebraic expressions, the respondents find improper combining of similar terms and improper distribution as the most difficult and sign errors as the least. The students recognized division as the most difficult operation to handle when manipulating algebraic expressions. Adjacent to division are subtraction and addition respectively. The students consider multiplication as the easiest operation to perform when dealing with algebraic expressions.

Thus, homework should be given to students to supplement and extend learning from the classroom to their home. Motivations should be given to students to utilize the library as an extension of the classroom. Mathematics teachers must develop the habit of giving a diagnostic test before a topic to determine the weak points of the students.

Keywords- Error analysis, operations of algebraic expressions, grade 8 students, KSU-Laboratoty High School.

\section{INTRODUCTION}

Education has been considered as one of the most basic concerns in the survival of the nation. Changes of curriculum are being done to keep up with the changing time (Agustin 2009). In the Philippine Educational System, the Department of Education is continuously working on the quality of education in the country today. Teachers are greatly challenged to innovate teaching - learning resources and integrate evidence - based strategies in order to enrich the curriculum. The Department of Education gives its best effort in developing and improving its program as well as conducting trainings, seminars and workshops to all educators nationwide to update and equip them with skills and knowledge needed to fill in the present needs of the declining quality of education. Despite the efforts to improve the quality of education, several changes are still being encountered in the teaching - learning process. One problem is the teacher is left thinking on the ways on how to handle the needs of the different kinds of learners. 
The central goal of education is to help a person develops critical thinking, reasoning and problem - solving skills (RA 10533 Enhanced Education Act of 2013). Hence, education prepares a person for life. One subject that helps people for life is Mathematics.

What is Mathematics? Most students would say it has something to do with numbers but numbers are just the type of mathematical structures. Math is used by everyone. It can be used anytime and anywhere. It is part of our life from cooking to eating, we used mathematical concepts.

The concept of Mathematics is used by scientists and programmers in creating and running high technology products. Wade and Taylor (1966) claimed that the fundamental principles of Physics, Biology and other basic sciences are the result of many measurements and many computations. Furthermore, (Layson 1988) postulates that Mathematics should aim equipping the child with Mathematical skills necessary for daily life.

Mathematics is the science of numbers and their operations, interrelations, combinations, generalizations, and abstractions and of space configurations and their structure, measurement, transformations and generalizations. (Merriam - Webster Dictionary) It is concerned chiefly on how ideas, processes and analyses are applied to create useful and meaningful knowledge. Mathematics also forms the basis of all discoveries and inventories and it has played a very important role in building up our civilization by perfecting all the Sciences. It gives a workable symbolism for the brief and precise expression of ideas to all Sciences. In the report of the Education Commission (1964-66), it is recommended that Sciences and Mathematics should be taught on the compulsory basis to all students as a part of general education during the first ten years of education. A difficulty in learning Mathematics is not generally a number based one but can be concept based or competency based. Some children learn to solve problems by mastery of steps in a procedure with a fixed order and errors appear when the problem is presented in a different format or when the test is made up of a variety of problems (Chamundeswari, S. 2014). Conceptual Errors Encountered in Mathematics Operations in Algebra among students at the secondary level (International Journal of Innovative Science, Engineering \& Technology, Vol. 1 Issue 8 , October 2014)

Basically, the students' first encounter in the study of Mathematics involves simple counting then they are exposed to the four fundamental operations of Arithmetic. Usually, following the Philippine Educational System, when students reach grade seven, they start to study Algebra (Johnson and Johnson 2004).

Valderama (2000) as cited by Gapasin (2010) stated that Algebra is the language through which most Mathematics is communicated. Generally, Algebra is a branch of Mathematics concerning the study of the rules of operations and relations, and the constructions and concepts arising from them, including terms, polynomials, equations and algebraic structures (Merriam - Webster Dictionary).

Algebra is regarded as the foundation of higher Mathematics branches such as Geometry, Trigonometry, Calculus and even Statistics. However, many attempts to better prepare students for Algebra have not resulted in greater achievement in first year Algebra. Students in grade 8 and grade 9 are still struggling with algebraic concepts and skills (Greens and Rubentein, 2008). Many are discontinuing their study of higher level Mathematics because of their lack of success in Algebra. The demand for Algebra at more levels of education is increasing (Wikianswers (2010), What is the importance of Algebra in today's world?) One of the world's lending questions and answers websites lists some of the uses of Algebra in today's world. Algebra is used in companies to figure out their annual budget which involves their annual expenditures. Various stores used Algebra to predict the demand of a particular product and subsequently place their orders. Algebra also has individual applications in the form of calculations of annual taxable income, bank interest, instalment and loans (http://wiki.answers.com/Q/What_is_the_importance_of_alg ebra_in_today's_world.).

Algebraic Expressions and Equations serve as models for interpreting and making inferences about data. Further, Algebraic reasoning and symbolic notation also serve as the basic for the design and used of consults, spreadsheets models. Therefore, Mathematical reasoning developed through Algebra if necessary all through life, affecting decisions we make in many areas such as personal finance, travel, cooking and real state. Thus, it can be argued that a better understanding in Algebra improves decision making capabilities in society. More analysis is necessary in order to develop a clear understanding of what factors help students to be successful in Algebra and how schools and other system can assist in achieving this goal. We already know that even very basic concept such as addition of whole numbers involves complicated cognitive process. 
Although there are many causes of student difficulties in Mathematics, the lack of support from research for teaching and learning is noticeable. If research could characterize students' errors and misconceptions, it would be possible to design effective instruction to avoid those situations. Research on students' errors and misconceptions is a way to promote such support for both teachers and students.

If researches can identify students' difficulties collectively in more than one area, it will be easier to identify the systematic patterns of errors (if there are any) that spread through the areas and make suggestions for remediation. In this context, this study is significant because it addresses the errors made by grade 8 students.

The researcher wants to expose the common weaknesses of grade 8 students at Kalinga State University Laboratory High School in terms of evaluating Algebraic Expressions. Awareness of such errors will benefit both the students and the teachers. The researcher wants to find out some factors that may contribute to such weaknesses. Consciousness of the different factors contributing to the commission of errors in evaluating algebraic expressions will alleviate the attempt of the student in eliminating such factors.

Tinggangay (2003), mentioned that to solve the common errors of students is to determine them and define the contributory factors to such errors, then conceptualized necessary measures and actions to eliminate the identified factors. Imson (2002) defined that the error analysis is a careful study of errors committed by learners. It described and explained the causes and references of errors. Analysis of errors provides feedback in the learning and teaching process because the process goes beyond error collecting to relevant assessing, explaining and predicting.

Gunawardena Egodawatte (2009) underlined the importance for teachers to have a deeper knowledge of Mathematical content as well as insights into student thinking. Teachers must identify the fundamental ideas that need to be taught, and must understand the difficulties and misunderstanding that are likely to occur. Problems that can be solved using Algebra have different structures and processes. Using the same method to teach every student may not always work. Some diagnostic teaching is sometimes necessary. Classroom teachers should focus their attention on students who lack the capabilities of transition from Arithmetic to Algebra and also on students who use algebraic methods to solve problems that could have been solved using simple Arithmetic. Errors can be a powerful tool to diagnose learning difficulties and consequently direct remediation. Research using these interpretations of the role of errors has provided valuable contribution to mathematics education, such as an increased awareness of individual differences and difficulties in learning mathematics. An analysis of the variety of degree of wrongness among mathematical errors can help clarify the nature of truth in mathematics. (Borasi R. 1987. Exploring Mathematics through analysis of errors. FLM Publishing Association Montreal, Quebec, Canada. Flmjournal. Org. accessed on July 6, 2016).

This study looked into the weaknesses of the students by analyzing the errors committed on the operations of Algebraic Expressions. The researcher analyzed the common errors committed on the operations involving Algebraic Expressions of the grade 8 students at Kalinga State University Laboratory High School; and, analyzed in which operation do the students usually commit errors when working with Algebraic Expressions.

\section{METHODOLOGY}

This research used the qualitative descriptive type research method which intends to observe, describe, analyze and document the needed data for the study. The data were generated through series of tests which were properly analyzed. There were four sets of tests that were administered by the subject teacher. The tests covered the four fundamental operations on Algebraic Expressions. The study was conducted at KSU - Laboratory High School in Bulanao, Tabuk City, Kalinga. The population of the study was composed of three sections namely Narra, Molave and Melina with a total of 135 students.

An assessment test was used to gather data on the errors committed. The results of the tests administered will be analyzed. There were four sets of tests. First is on addition and subtraction of Algebraic Expressions, second is on multiplication, third is on division then the last is the combination of the four operations to ensure accurate data. An interview was also used to gather information regarding the analysis of errors. The researcher randomly selected 10 students from each section and their responses were recorded and analysed.

The data were gathered by administering the tests and analyzed. Since this study is qualitative, the analyzed results of the study were presented in tables and graphs. The figures presented discussed the errors committed and the operations where the respondents usually committed errors. 
The table below is the schedule of administering the questionnaires.

\section{A. ERRORS IN COMBINATION OF TERMS}

\section{RESULTS AND DISCUSSION}

This study sought to analyze the common errors committed by the grade 8 students at Kalinga State University Laboratory High School.

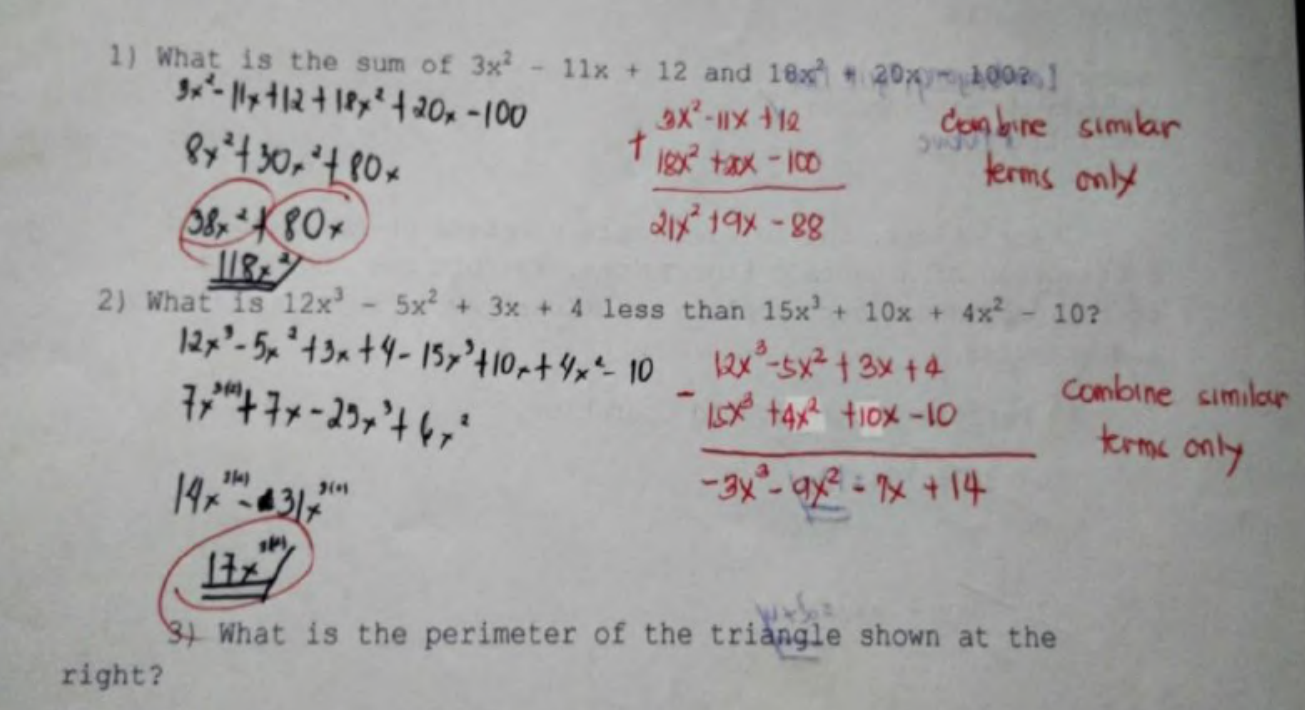

The picture shows an error on improper combination of terms. In problem number 1, the student combined these terms $38 x^{2}+80 x$, which should not be. The students forgot the rule on addition of Algebraic Expressions which is to combine similar terms only. The terms $38 x^{2}+80 x$ are not similar terms, thus it cannot be combined.

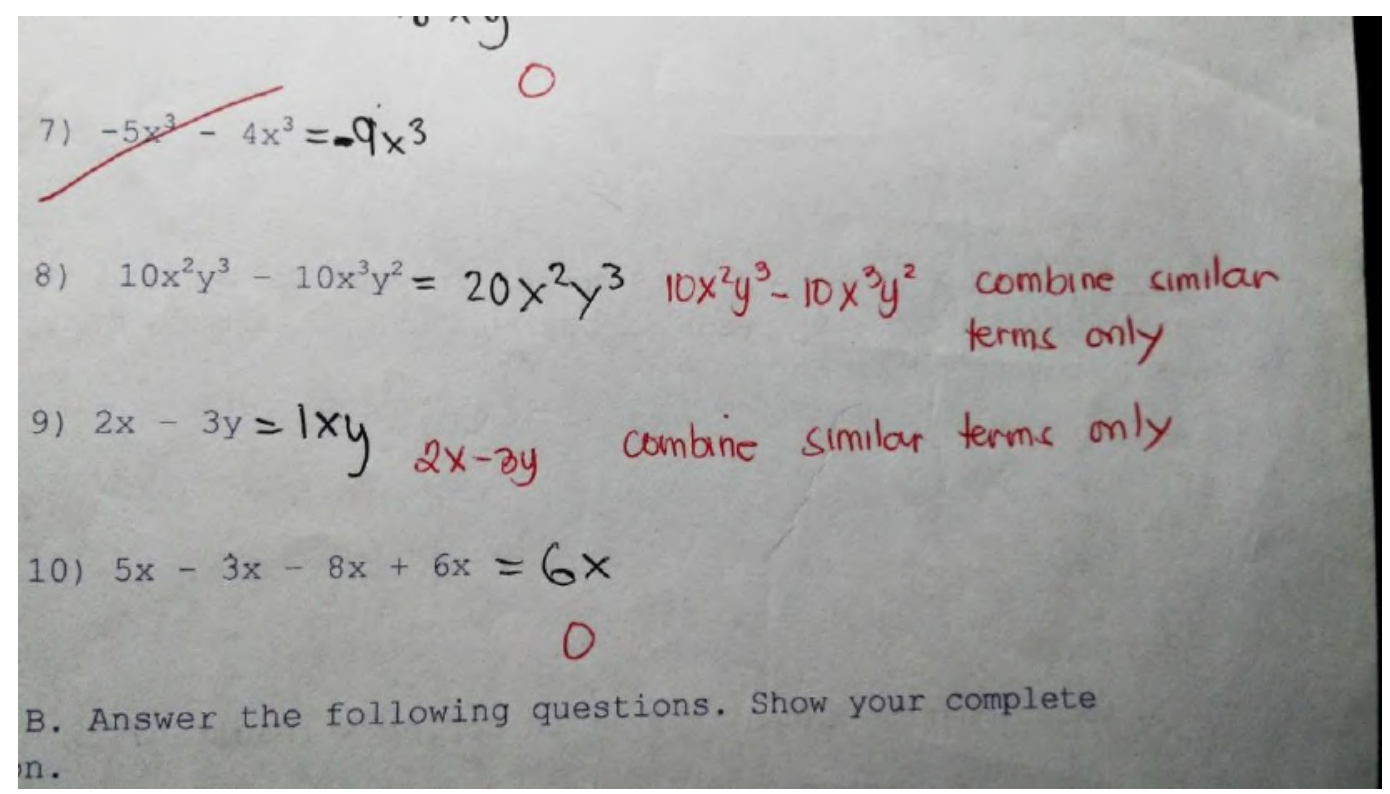

The picture shows errors on improper combination of terms. In problem number $8,10 x^{2} y^{3}-10 x^{3} y^{2}$ were combined which should not be. The two terms have the same numerical coefficients and the same variables but different exponents to corresponding variables; thus, the two terms are not similar terms. 


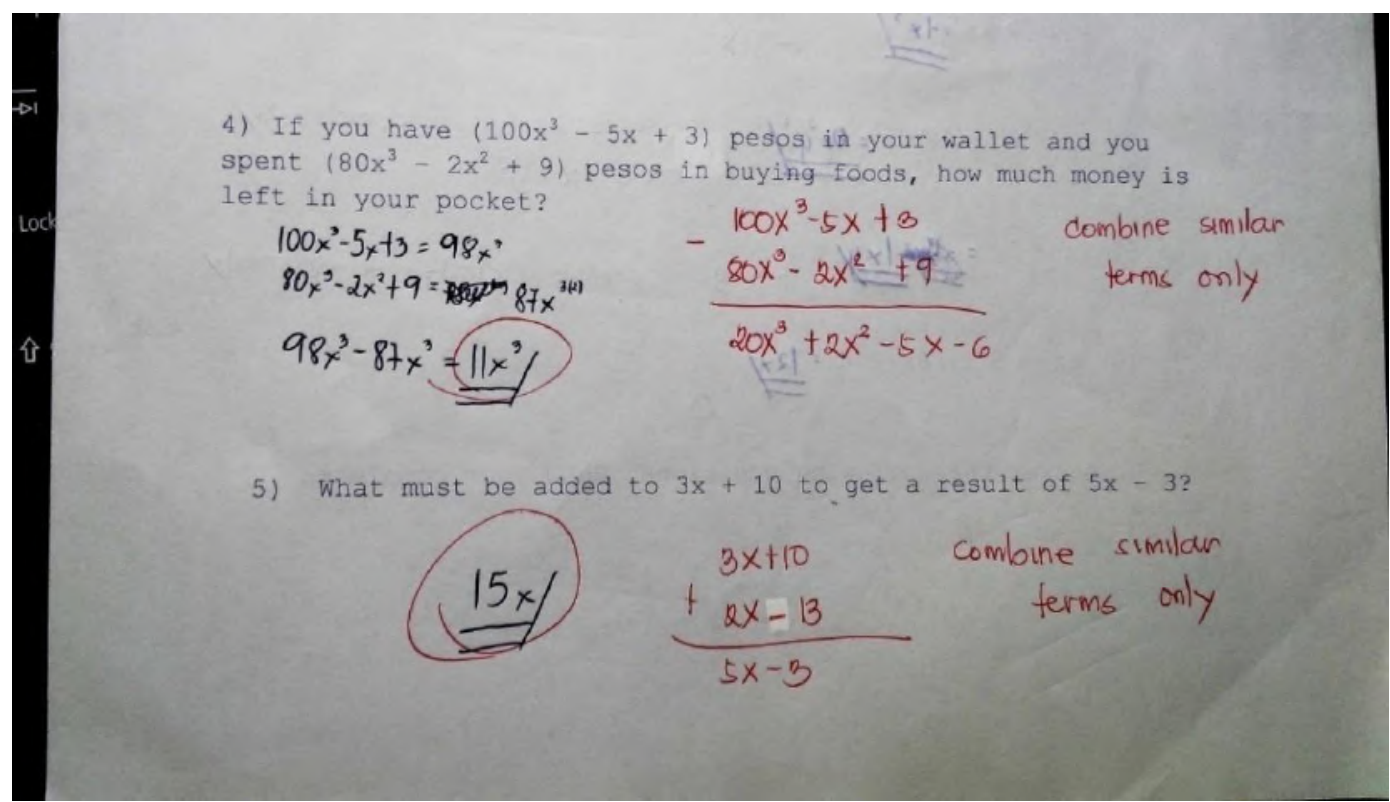

The pictures show the error on improper combination of terms. Students usually commit this error because they tend to forget the law/rule of addition and subtraction of algebraic expression as evident in the picture above. In problem number 4 above, the students combined $100 x^{3}-5 x+93=98 x^{3}$. This expression cannot be combined because the terms are not similar. Students usually considered $x^{3}$ and $x$ as similar terms, they forgot that it contains different exponents; thus, dissimilar terms.
According to some students when the researcher asked them why they combined terms that are not similar, they responded, "Nakakalito kasi ang alam ko kapag pareho ang variable puwedeng mag combine" (It is confusing, what I know that if the terms have the same variables, it can be combined).

From their response, students were confused in determining which are similar terms.

\section{B. ERROR ON IMPROPER DISTRIBUTION}

Avola superımpositions ana erasures.

\section{A. Simplify the following Algebraic Expressions:}

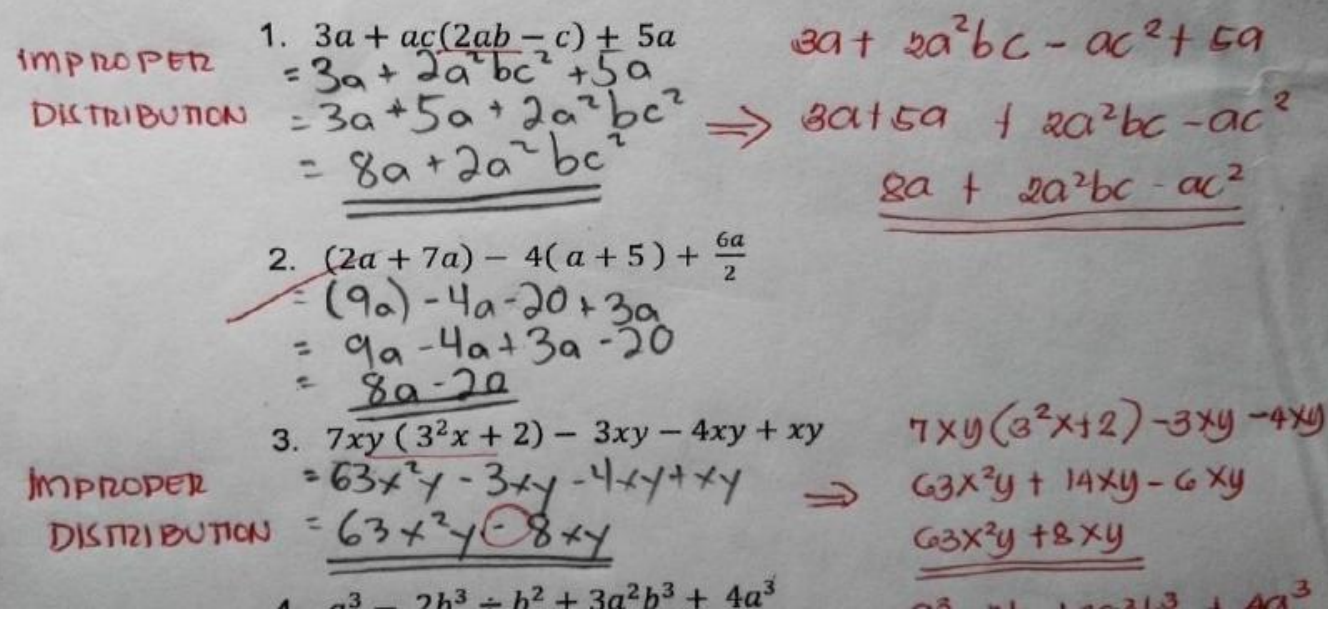

The picture shows an error on improper distribution of terms. In question number $1,3 a+a c(2 a b-c)+5 a, a c$ should be distributed to the terms inside the parenthesis however, students distributed ac to the first term inside the parenthesis only which is wrong. Students just multiply the first term by the coefficient and ignore the second term. In problem number 1 in the picture 
clearly showed improper distribution, the expression $a c(2 a b-c), a c$ was properly distributed to the first term $2 a b$ and it became $2 a^{2} b c$ but it was not distributed to the second term $-\mathrm{c}$.

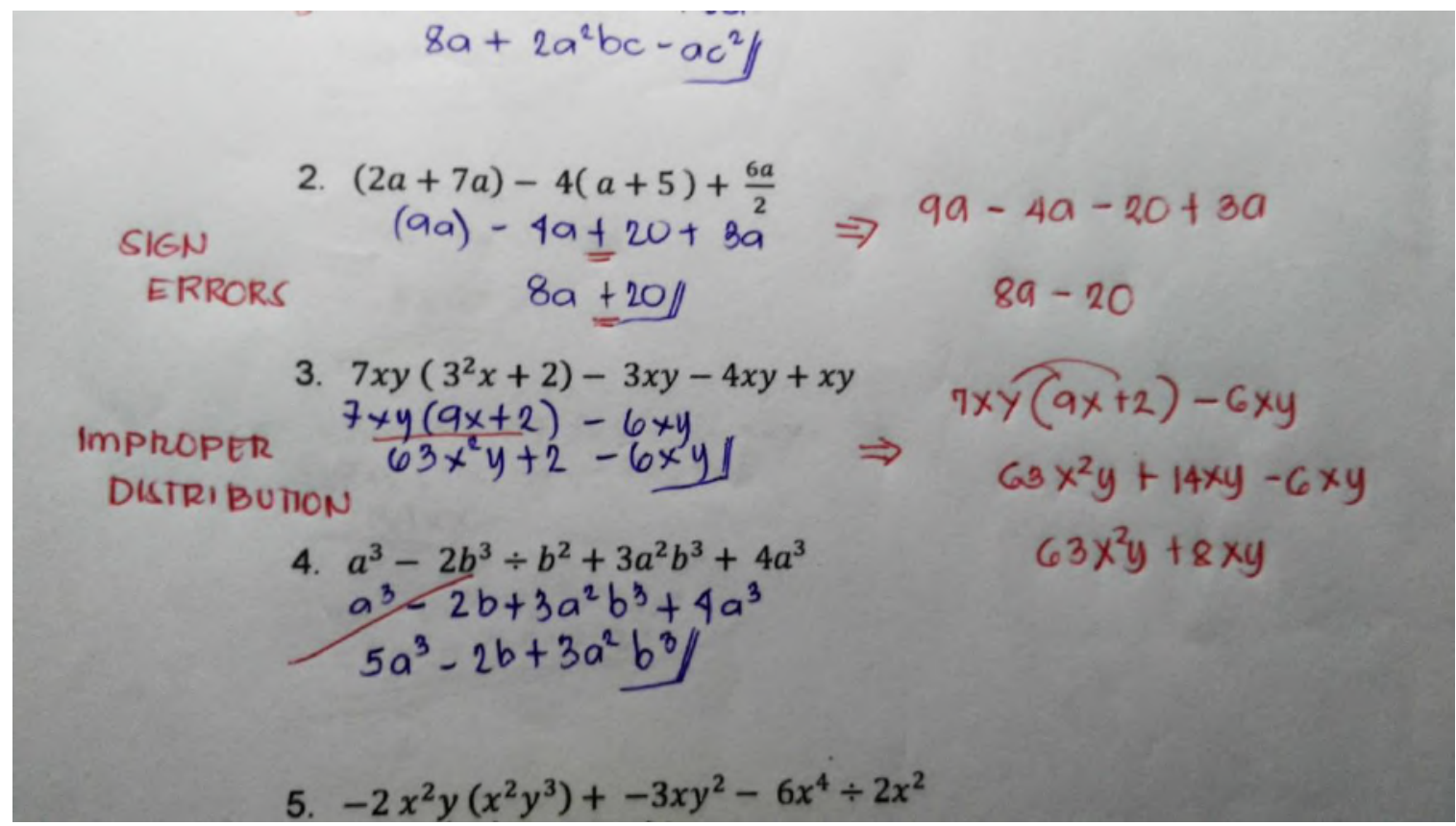

The picture shows an error on improper distribution. In number three problem above is the expression $7 x y\left(3^{2}+\right.$ 2) of which $7 x y$ was distributed to the first term $3^{2}$ but failed to distribute it to the second term 2 . This is especially true when the second term is just a number.

The researcher interviewed some students regarding this error, the students responded, "Hindi ko maintindihan ang expression, kaya hindi ko alam sagutin" ( I don't understand the expression that's why I don't know how to answer). Another response from the students, "pugpugto ti answer mi" (Our answers were just mere presumptions.)

This implies that students did not understand the problem.

\section{ERROR ON CANCELLATION}

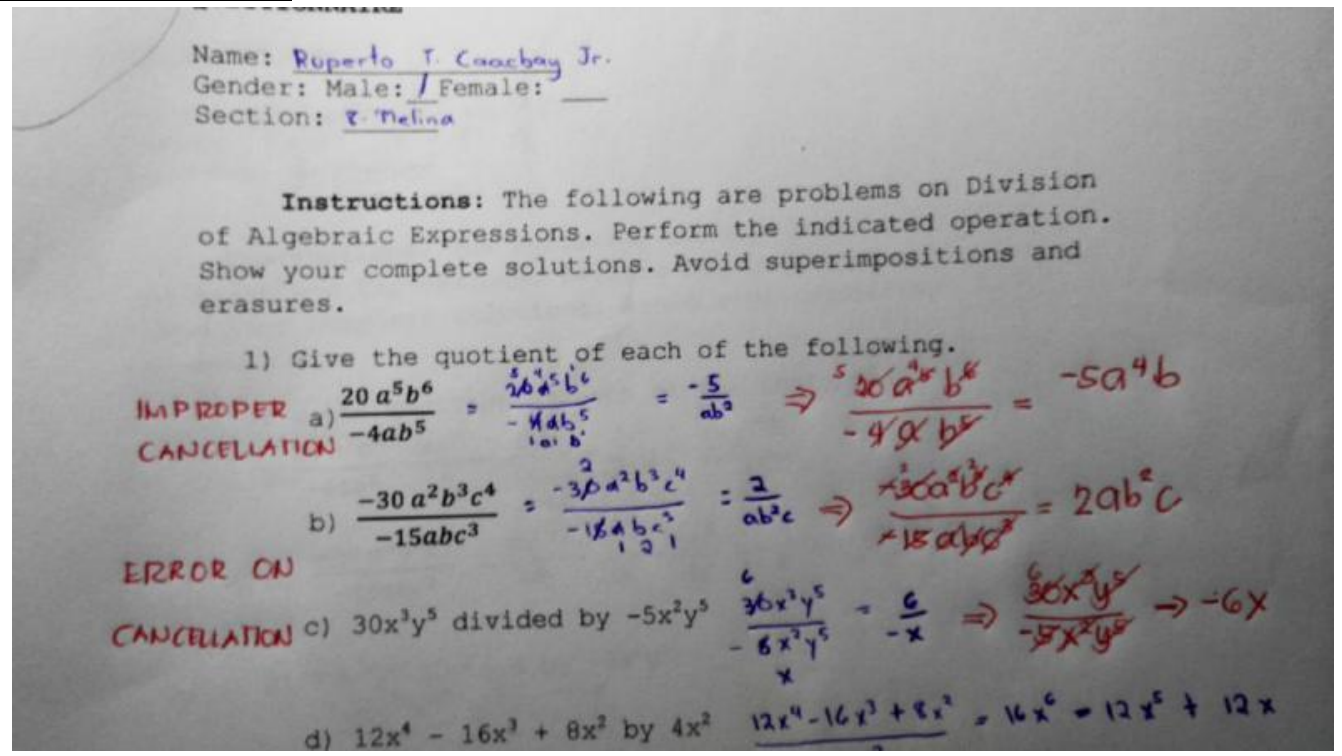

The picture shows errors on cancellation that students often make in solving algebraic expressions. Any quantity to be cancelled must be a common factor of the entire numerator and the entire denominator. If the numerator and 
the denominator have no common factor then the expression cannot be simplified. In example $1 \mathrm{a}, \mathrm{b}$ and $\mathrm{c}$ in the pictures are examples of an improper cancellation or a violation of the quotient rule that states when simplifying fractions involving variables, subtract the smaller exponent from the greater exponent. Place the resulting variable in the same position (numerator or denominator) as the variable with the greater exponent. In the expression $\frac{20 a^{5} b^{6}}{-4 a b^{5}}$ of problem number 1 above, if we subtract the exponents, the variables will stay in the numerator part because the exponents in the numerators are bigger than the exponents in the denominator. So the final answer is $-5 a^{4} b$ as shown in the picture.
The researcher interviewed some students why did they commit errors on cancellation. They responded:

Student A: I am confused whether to add or subtract the exponents.

Student B: "Basta nu agpada ket macancel" (If it is the same, it will be cancelled.)

The responses of the students show that they really need to be oriented and to be taught on the rules of the simplification of algebraic expressions. Student B neglected the use of the variables both in the numerator or denominator. Even if the variables are the same if it is used as minuend or addend; it cannot be cancelled unless the use is factors.

\section{ERROR ON REMOVAL OF SYMBOLS OF INCLUSIONS}

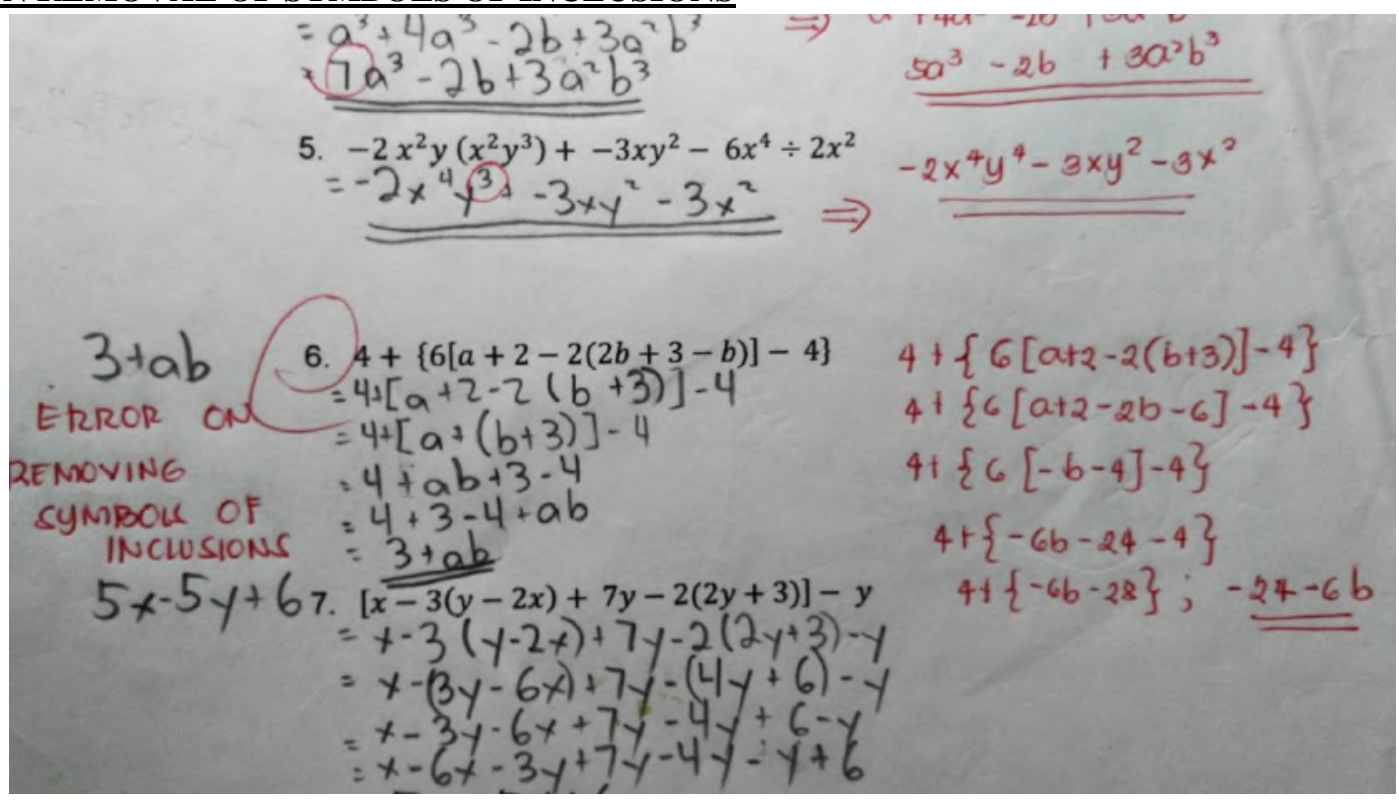

The picture shows an error on improper removal of symbols of inclusions. In problem number 6 above, -2 was supposed to be distributed to all the terms inside the parenthesis. In the expression, $6[a+2-2(2 b+3-b)], 6$ is not properly distributed to the terms inside the bracket; thus, the student failed to remove the bracket in the problem. The red ink showed the proper way of solving the problem.
The reason for this is some students do not follow the PEMDAS rule that says "always solve and remove the numbers inside the parenthesis or symbols before proceeding on to simplifying" and intend to solve first the number outside the symbol before including the numbers inside the symbol. 


\section{E. SIGN ERRORS}

$$
\begin{aligned}
& \text { 7. }[x-3(y-2 x)+7 y-2(2 y+3)]-y \quad[x-3 y+6 x+7 y-4 y-6]-y \\
& \begin{array}{l}
{[x-3 y+6 x+7 y-4 y-6]-y \Rightarrow[7 x-6]-y} \\
{[7 x-6]-y}
\end{array} \\
& =7 x-6-y 1 \\
& 7 x-6-y \\
& -\left[2 a^{2}-a-5 a^{2}-3 b-4 a^{2}+2 b\right] \\
& -\left[2 a^{2}-a-5 a^{2}+3 b-4 a^{2}+2 b\right] \\
& \begin{array}{r}
-\left[-7 a^{2}-a-b\right] \\
\left.7 a^{2}+a+b\right]
\end{array} \\
& \Rightarrow-\left[2 a^{2}-5 a^{2}-4 a^{2}-a+3 b+2 b\right] \\
& -\left[-7 a^{2}-a+5 b\right]
\end{aligned}
$$

\section{Dila}

The picture shows an error involving signs. In question 8 , the expression inside the bracket is preceded by a negative sign. In the example above, the student failed to distribute the negative sign inside the bracket and it's a common error they usually commit. The correct step in answering is shown in the picture above. Some students forget the rule that every time we multiply a positive integer and negative integer, the product will always be a negative integer.
The researcher asked some students what is confusing when simplifying algebraic expressions with different signs, and they responded that they are confused when the bracket or parenthesis is preceded by a negative sign.

From the response of the students, it is clear that they find difficulty in simplifying algebraic expressions that involves different signs. Other students just neglect the negative sign that's why they usually commit errors.

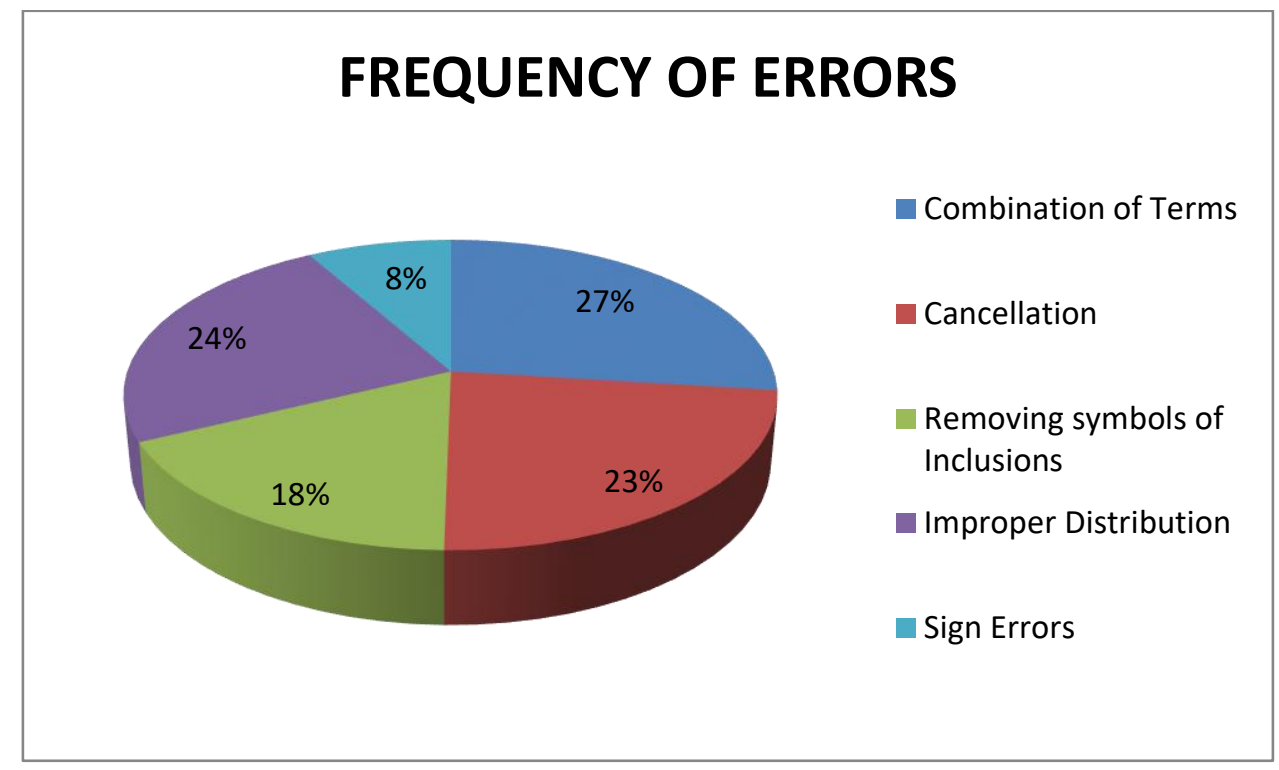

Fig.3: Frequency of Errors Committed 
Figure 3 shows that combination of terms is ranked first among the five errors committed with $27 \%$. This can be premised from the students' incompetency in determining similar and dissimilar terms as perceived from the solutions of the test questions. Improper distribution ranks second with $24 \%$, this implies that the respondents are not knowledgeable enough when asked to distribute terms to a group of terms inside the parenthesis or bracket or on braces. The respondents tend to neglect to distribute a monomial to all the terms of a polynomial when asked to multiply such expressions. An example can further elaborate this interpretation:

Algebraic Expressions Wrong Procedure Correct Procedure

$$
7 x(9 x+2) \quad 63 x^{2}+2 \quad 63 x^{2}+
$$

$14 \mathrm{x}$

Cancellation ranks third with $23 \%$, this only means that the respondents do not actually know when to cancel algebraic terms. They are not equipped of the basic rules of cancellation like when dividing terms; terms that are used as factors in the numerator part can be cancelled if they have similar terms in the denominator part. Removing symbols of inclusions ranks fourth with $18 \%$, students simply remove symbols of inclusions without taking into consideration the sign or any term preceding or succeeding the symbols of inclusions. Sign errors rank fifth with $8 \%$ which signify that the respondents have not yet mastered the basic rules concerning signs. They often forget to carry the signs of the term with it.

The five common errors presented in this study play a significant role towards the success of every student in learning higher mathematics especially Algebra. This result agrees with the claim of Gapasin (2010) in his findings in which he found out that the common errors on Operations of Algebraic Expressions are the same as the findings in this study. Furthermore, the rank of the number of frequency of errors is the same as the rank of the number of frequency of errors in this study.

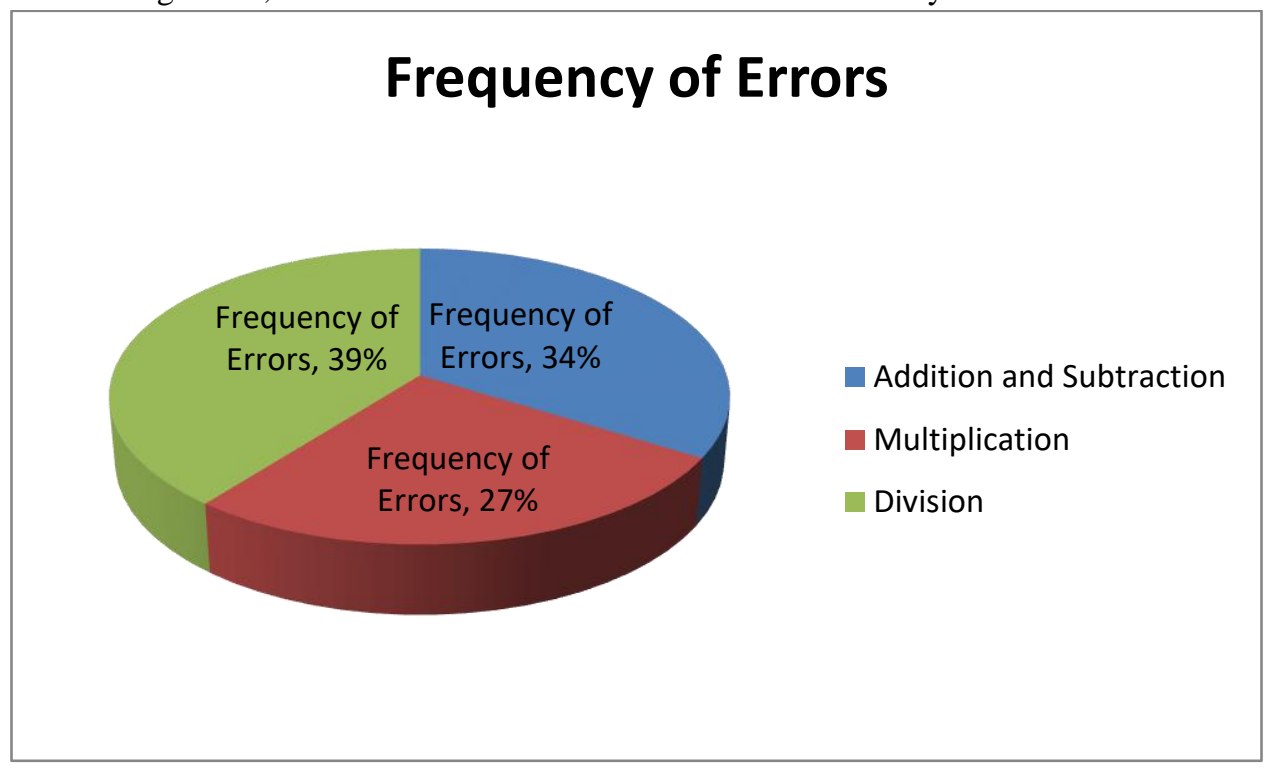

Fig.4: Frequency of Errors of the four operations

Division is ranked first (1) with $39.39 \%$ for the frequency of the number of errors committed, this implies that students found division to be the most difficult operation of Algebraic Expressions. It is evident from Table 7 that the respondents find Division as the most difficult when operating on Algebraic Expressions. This result agrees with the claim of Dongbo (1989) as cited by Gapasin (2010)findings in which he found out that elementary children do not have a good mastery of Division. Deducing from the test papers of the respondents, they often fail to carry out the proper procedure especially concerning exponents and variables.

Ranked second (2) is addition and subtraction, discerning from the output of the respondents, they are confused on how to deal with the variables and exponents. This falls back to determining similar terms. Another is they do not know how to employ the properties of integers under subtraction and addition. This error regresses to sign errors. This indicates that several of the respondents are not yet masters of this operation. Addition of algebraic expression is supposed to be 
an easy task. However the inability to recognize similar terms deters the students from successfully carrying out operation in addition. Furthermore, the students' inadequacies in combining terms and in signed numbers contribute to faulty addition and subtraction of algebraic expressions. The process of multiplication of algebraic expressions is ranked third of the total errors committed on all the four fundamental operations. Obviously, it still presents a large quantity of errors. This only shows that even though multiplication has the least errors committed comparing to the other fundamental operations, it is still disturbing that a large committed under such simply and direct operation. This result is relatively similar to the result of Gapasin (2010), in his study showed division, subtraction, multiplication and addition in that order of descending difficulty, but Rimban's (1986) as stated by Gapasin, the result showed that addition is the easiest among the four fundamental operations where as in this study; multiplication came out to be the easiest.

\section{CONCLUSION}

When working on Algebraic Expressions, the respondents found combining of similar terms and improper distribution as the most difficult and sign errors as the least committed. Also, the students recognized division as the most difficult operation to handle when manipulating algebraic expressions. Adjacent to division are subtraction and addition respectively. The students consider multiplication as the easiest operation to perform when dealing with algebraic expressions.

\section{RECOMMENDATIONS}

Mathematics teachers must develop the habit of giving a pre - assessment test before a topic to determine the weak points of the students thus, allotting more time to the teacher to determine if the students have really developed a solid understanding of the previous lessons. Homework should be given to students to supplement and extend learning from the classroom to their home. Teachers should also motivate the students to utilize the library as an extension of the classroom. A similar study may be conducted on a wider scope to determine particular mathematics topics where students usually find difficulty. Upon which, the higher and proper authorities can devise learning plans and textbooks to address such difficulties.

\section{REFERENCES}

[1] Aguele, L.(2010). Effectiveness of Selected Teaching Strategies in the Remediation of Process Errors Committed by Senior Secondary School Students in Mathematics. Journal of Social Sciences, 22(2), pp. 139-144.

[2] Borasi, R. (1987). Exploring Mathematics through analysis of errors. Quebec, Canada: FLM Publishing Association Montreal, Flm- journal. Org. retrieved on Sept. 6, 2018).

[3] Borasi, R. (1994). Capitalizing on Errors as "Springboards for Inquiry": a Teaching Experiment, Journal for Research in Mathematics Education, Vol. 25, No. 2, pages 166-208.

[4] Chamundeswari, S.(2014). Conceptual Errors Encountered in Mathematics Operations in Algebra among students at the secondary level. International Journal of Innovative Science, Engineering \& Technology, Vol. 1 Issue 8, October 2014 retrieved on October 20, 2018 at www.ijiset.com

[5] Egodawatte, G. (2011). "Secondary School Students' Misconceptions in Algebra". Published Dissertation, University of Toronto.

[6] Egodawatte, G. (2009). "Is Algebra Really Difficult for all students” @ http://adn.teaching.roarticle_2_4_10.pdf. Retrieved on October 8, 2018

[7] Gapasin, R. (2010). "Errors Committed in the Operations of Algebraic Expressions Of First Year High School in Saint Louis Aurora Hill". Unpublished Master's Thesis, Benguet State University, La Trinidad, Benguet.

[8] Garces, I. \& DepEd Development Team (2013), Learners' Module Grade7 (First Edition), Department of Education Instructional Materials Counsil Secretariat, Pasig City, Philippines.

[9] Greens, C. E. and Rubenstein, R. (2008). Algebra and Algebraic Thinking in School Mathematics. Seventieth yearbook, NCTM.

[10] Gumpo, L. (2014). Grade 9 learners' strategies and errors in solving arithmetic and algebraic linear equations Retrieved on $\begin{array}{llll}\text { October } & 18, & 2018 & \text { from }\end{array}$ file:///E:/Lethu\%20Gumpo\%20Research.pdf

[11] Imson, G. T. (2002). “Newman's Method in Analyzing Causes of Errors Committed by Freshmen in Solving Mathematical Problems in Baguio City". Unpublished Master's Thesis, Saint Louis University, Baguio City.

[12] Hall, R.(2002). "An Analysis of Errors Made in the Solution of Simple Linear Equations".retrieved on October 18, 2018 @ www.people.ex.ac.uk/PErnest/pome 15/r_hall_expression.pdf

[13] Johnson, R.E. and C. G. Johnson (1996). Algebra, The language of Mathematics. Fay Thomas Bakhru, Rose TreeMedia School District Media, Pennyslvania.

[14] Müller, T.J., Cury, H.N. and de Lima, J.V. (2014). A Discussion about Errors in Algebra for Creation of Learning Object. International Journal of Contemporary Educational Research, 1(1), pp. 42-50.

[15] Schoenfeld, A. H. (1992). Learning to think mathematically: Problem solving, metacognition, and sense making in 
mathematics. In D. Grouws. (Ed.), Handbook of Research on Mathematics Teaching and Learning. (pp. 334-370). NY: Macmillan Publishing Company.

[16] Tinggangay, D. B. (2003). "Difficulties of First Year Students in Mathematics in the Public Schools of Tanudan, Kalinga Division as perceived by themselves". Unpublished Master's Thesis, Saint Louis College of Bulanao, Bulanao, Tabuk City.

[17] Wade, T. L. (1966). Fundamental Mathematics. McGraw Hill Book Company, Inc., New York: Toronto, London.

[18] WikiAnswers(2010). What is the importance of Algebra in today's world?. 